\title{
Effects of Er-Miao-San extracts on TNF-alpha-induced MMP-1 expression in human dermal fibroblasts
}

\author{
Seunghee Bae ${ }^{1 \dagger}$, Younjung Jung ${ }^{2 \dagger}$, Yeong Min Choi ${ }^{1}$ and Shunhua $\mathrm{Li}^{2,3^{*}}$
}

\begin{abstract}
Background: Various health benefits have been attributed to Er-Miao-San (EMS), a traditional Chinese herbal formulation that contains equal amounts of cortex phellodendri (Phellodendron amurense Ruprecht) and rhizoma atractylodis (Atractylodes lancea D.C). However, its effect on the anti-inflammatory activity in human dermal fibroblasts (HDFs) and the mechanism underlying this effect are unknown.

Results: This study investigated the effects of EMS on TNF-a-induced MMP-1 expression in HDFs. Our data show that EMS inhibited TNF-a-induced MMP-1 expression in a concentration-dependent manner. Interestingly, EMS maintained IKB content without inhibiting the phosphorylation of MAPKs, which are well-established upstream kinases of NF-KB. Moreover, EMS reduced the level of nuclear p65 protein in HDFs. Luciferase assay revealed that EMS inhibits the transcriptional activity of NF-KB by stabilizing IKB. Our results show that EMS exerts its anti-inflammatory effect by inhibiting NF-KB-regulated genes such as IL-1 $\beta$ and IL-8. Moreover, EMS effectively inhibited TNF-a-induced expression of MMP-1 via the NF-KB pathway.
\end{abstract}

Conclusions: Taken together, our data suggest that EMS could potentially be used as an anti-inflammatory and anti-aging treatment.

Keywords: Er-Miao-San, MMP1, Human dermal fibroblasts, TNF-a, NF-kB

\section{Background}

Skin aging can be divided into two types, namely intrinsic aging, which is caused by the natural consequences of physical change, and extrinsic aging, which is caused by exposure to environmental factors such as ultraviolet (UV) rays and pollutions [1]. Oxidative stress due to UVB, an extrinsic aging factor, causes DNA damage, and leads to human dermal fibroblast (HDF) senescence [2]. In addition, inflammation of skin cells caused by various environmental factors is also known to be a representative factor that induces skin aging [3].

Wrinkle formation is the most representative characteristic of skin aging, and is closely related to a reduction

\footnotetext{
* Correspondence: lixiao@konkuk.ac.kr

${ }^{\dagger}$ Equal contributors

${ }^{2}$ Department of Bioengineering, Graduate School of Konkuk University, Seoul, Republic of Korea

${ }^{3}$ Department of Beauty Education, Graduate School of Education, Konkuk University, 120 Neungdong-ro, Gwangjin-gu, Seoul 143-701, Republic of Korea

Full list of author information is available at the end of the article
}

in skin elasticity and degeneration of the extracellular matrix (ECM) [4]. The ECM consists of a mesh of fibrous proteins, such as collagen, elastic fibers, and glycosaminoglycans, which are generated by fibroblasts. These cells synthesize procollagen type- 1 (Col-1) and type-3 (Col-3) in the dermis and secrete matrix metalloproteinase (MMP), an enzyme that degrades nearly all ECM components, including collagen. Wrinkle formation is caused by the secretion of higher levels of MMP-1 and reduction of procollagen synthesis in HDFs [5]. Several compounds including cordycepin and brazilin have recently been suggested as possible anti-aging agents through suppressing the secretion of MMP-1 and MMP-3 in HDFs [6,7].

$\mathrm{NF}-\mathrm{kB}$ is one of transcription factors and forms homoand heterodimer complexes with Rel family proteins such as RelA (p65), RelB, cRel, p50, and p52 [8]. The transcriptional activity of NF- $\mathrm{KB}$ is mainly regulated by its intracellular localization, which is primarily controlled by inhibitor of $\kappa B(I \kappa B)$ [8]. I $\kappa B$ can dimer with $N F-\kappa B$, which induces cytoplasmic retention of NF- $\kappa B$ 
[9]. Upon lipopolysaccharide (LPS) or cytokine stimulation, I $\mathrm{B}$ kinase $(\mathrm{IKK})$ is activated and phosphorylates $\mathrm{I}_{\kappa} \mathrm{B}$, and then phosphorylated $\mathrm{I} \kappa \mathrm{B}$ underwent polyubiquitinationmediated proteasomal degradation [10]. Following the degradation of $\mathrm{I} \kappa \mathrm{B}, \mathrm{NF}-\mathrm{kB}$ translocates to the nucleus and induces transcription of various inflammatory genes, including interleukin (IL)-1 $\beta$ and IL-8 [11,12]. Accumulating studies have also shown that NF- $\mathrm{kB}$ regulates skin aging by regulating the expression level of $M M P-1$ in dermal fibroblasts $[13,14]$. Interestingly, it was reported that suppression of NF- $\mathrm{KB}$ activation reduces $M M P-1$ expression in HDFs and inhibits skin photoaging [15]. Furthermore, inflammation-induced activation of NF- $\mathrm{KB}$ causes deterioration of dermal tissue by promoting the expression of $M M P-1$, which exerts degradation of dermal type I collagen [16].

Er-Miao-San (EMS) is a compound commonly found in traditional Chinese medicine (TCM) that consists of equal amounts of Cortex Phellodendri (CP) and Rhizoma Atractylodis (RA). The major component of $\mathrm{CP}$, berberine, promotes the apoptosis of cancer cells by regulating caspase-3 [17]. In 3 T3-L1 adipose cells, free fatty acidinduced insulin resistance was recovered by berberine through activation of inhibitor of $\kappa B$ kinase- $\beta$ (IKK- $\beta$ ) [18]. Moreover, berberine prevents receptor activator of nuclear factor kappa-B ligand (RANKL)-induced NF- $\mathrm{kB}$ activation by blocking phosphorylation of inhibitor of $\kappa \mathrm{B} \alpha$ $(\mathrm{I} \kappa \mathrm{B} \alpha)$ [19]. RA extract has been known to inhibit the activity of cyclooxygenase-1 (COX-1) [20], 15-lipoxygenase [21], and thromboxane [22], as well as block the expression of interleukin (IL)-1ß/IL-6 [23] and IL-2 [24]. Studies have shown that RA also inhibits NF-kB [25], and that EMS exerts beneficial effects on prevention of cancer progression, inflammation, atherosclerosis, and arthritis $[26,27]$. However, little is known about the biological effects of EMS on skin aging.

TNF-alpha (TNF- $\alpha$ ) is one of the major inflammatory cytokines [28]. It was reported that TNF- $\alpha$ induces MMP1 expression and suppresses collagen synthesis in HDFs [28]. After TNF- $\alpha$ stimulation in cells, NF- $\mathrm{kB}$ is activated and acted as a transcription factor for $M M P 1$ expression $[8,13]$. Besides $I_{\kappa} B$, mitogen-activated protein kinases (MAPKs) are important signaling molecules that affect $\mathrm{NF}-\mathrm{\kappa B}$ activation [29], as evidenced by the lack of NF- $\mathrm{KB}$ transactivation following MAPK inhibition [29]. Here, we demonstrated that treatment with EMS inhibits TNF- $\alpha-$ induced $M M P-1$ expression through suppressing NF- $\mathrm{kB}$ nuclear localization in HDFs. Also, we observed that EMS-mediated NF- $\mathrm{kB}$ inhibition was not dependent on MAPK signaling pathways in HDFs.

\section{Results}

\section{Effect of EMS on cell viability}

We first investigated whether the treatments of EMS, CP and RA on human skin dermal fibroblasts will induce cytotoxic or non-cytotoxic properties, and what are the non-cytotoxic concentration ranges of EMS, CP and RA on human skin dermal fibroblasts before further experiments that investigate the EMS-induced protection effect on TNF- $\alpha$-induced $M M P-1$ expression. Therefore, we set the experimental conditions as followed; the treatment concentrations is $0-1000 \mu \mathrm{g} / \mathrm{ml}$, and the treatment time is $24 \mathrm{~h}$. To examine the cytotoxicity of EMS, CP, and RA, HDFs were treated with various concentrations (0$1000 \mu \mathrm{g} / \mathrm{ml}$ ) of the reagents for $24 \mathrm{~h}$, and the WST- 1 assay was performed to evaluate cell viability. As shown in Figure $1 \mathrm{~A}$ and $\mathrm{C}$, treatment with EMS and RA slightly increased the cell viability of HDFs as the concentration increased. Interestingly, treatment with less than $500 \mu \mathrm{g} /$ $\mathrm{ml} \mathrm{CP}$ did not induce any significant cytotoxicity relative to the control; however, the viability was decreased to 75.1\% when HDF cells were treated with $1000 \mu \mathrm{g} / \mathrm{ml} \mathrm{CP}$, respectively (Figure $1 \mathrm{~B}$ ). Therefore, we concluded that although larger dose of CP $(1000 \mu \mathrm{g} / \mathrm{ml})$ show cytotoxicity in HDFs, EMS, which contain equal amount of $\mathrm{CP}$ and $\mathrm{RA}$, is not cytotoxic reagent in HDFs, and the doses of

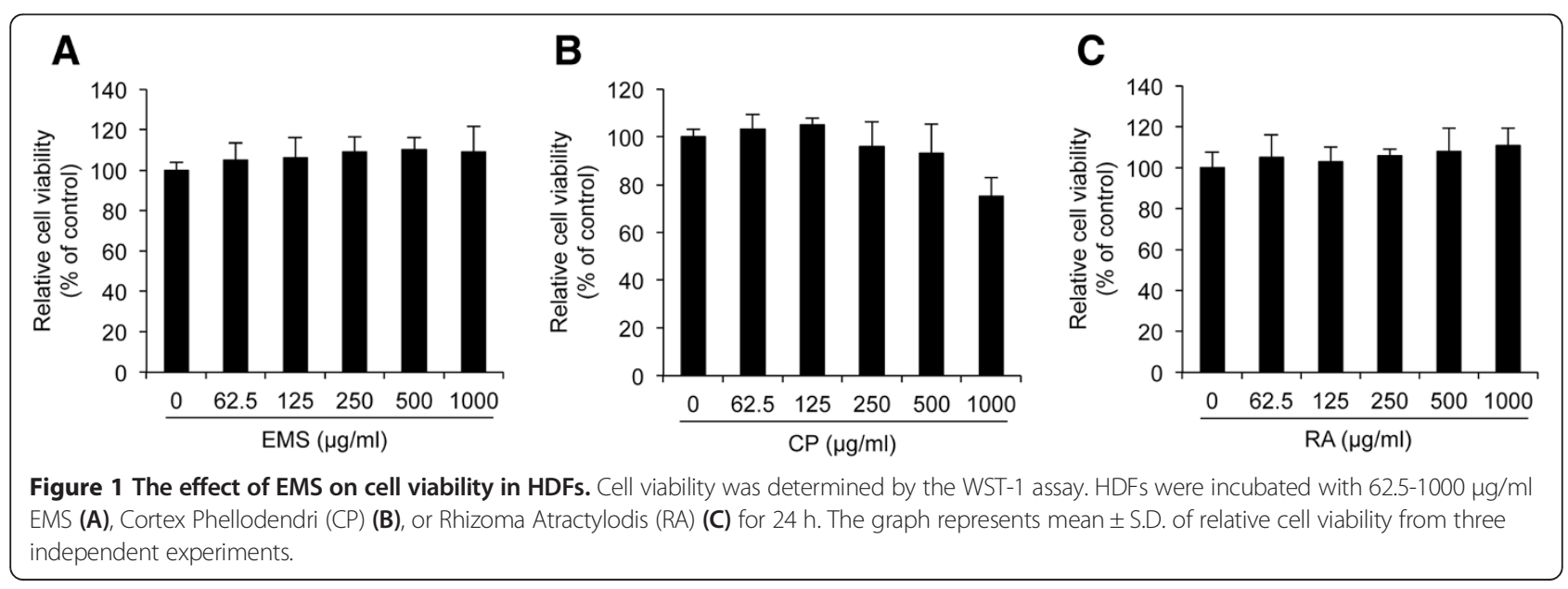


250 and $500 \mu \mathrm{g} / \mathrm{ml}$ EMS, CP and RA were used in further experiments.

Effect of EMS on TNF-a-induced expression of MMP-1 mRNA We next investigated whether TNF- $\alpha$-induced downregulation of $M M P 1$ expression could be regulated by treating EMS in HDFs. HDFs were seeded and pretreated with 250 and $500 \mu \mathrm{g} / \mathrm{ml} \mathrm{EMS} \mathrm{for} 3 \mathrm{~h}$, and then exposed to TNF- $\alpha$ for $4 \mathrm{~h}$. After TNF- $\alpha$ stimulation, cells were gathered and the expression level of $M M P 1$ was investigated using RTPCR with its specific primers. As shown in Figure 2A, TNF- $\alpha$ increased the expression level of MMP1 by $6.75 \pm$ 0.81 fold compared with non-treated control cells. However, 250 and $500 \mu \mathrm{g} / \mathrm{ml}$ EMS treatments before TNF- $\alpha$ stimulation significantly inhibited the expression level of

\section{A}

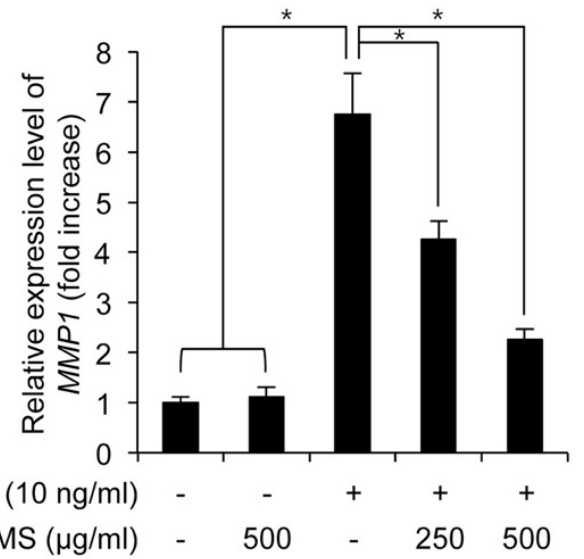

B

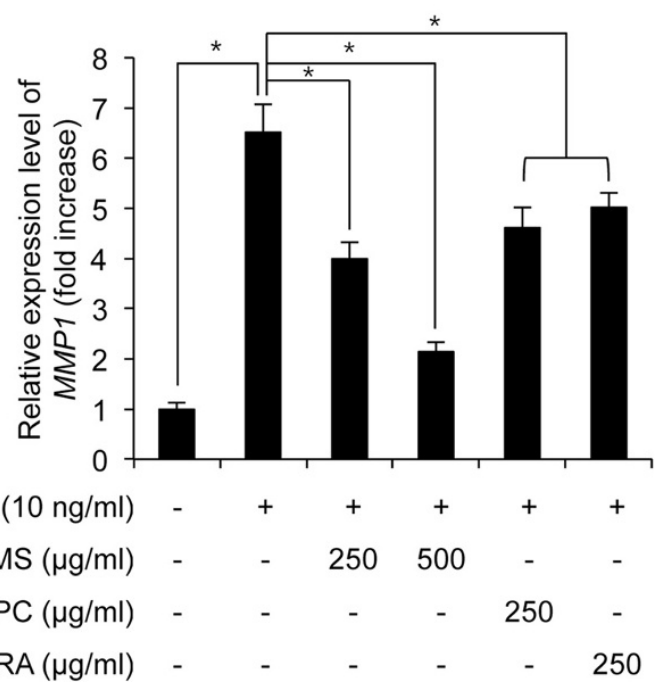

Figure 2 The effect of EMS on TNF-a-induced MMP-1 mRNA expression in HDFs. HDFs were pre-treated with $250-500 \mu \mathrm{g} / \mathrm{ml}$ EMS (A), $250 \mu \mathrm{g} / \mathrm{ml} \mathrm{CP}$ and $250 \mu \mathrm{g} / \mathrm{ml}$ RA for $3 \mathrm{~h}$ (B), and subsequently stimulated with $10 \mathrm{ng} / \mathrm{ml}$ TNF-a for $4 \mathrm{~h}$. The level of MMP-1 mRNA was determined by qRT-PCR. Independent experiments were performed in triplicate $\left({ }^{*} \mathrm{p}<0.05\right)$.
MMP1 by $4.26 \pm 0.37$ and $2.26 \pm 0.21$ fold, respectively, as compared with non-treated control cells (Figure 2A). Of note, the upregulated MMP1 expression induced by TNF$\alpha$ was largely downregulated to $33.57 \%$ in $1000 \mu \mathrm{g} / \mathrm{ml}$ EMS pretreated HDFs as compared with TNF- $\alpha$ treated cells. Furthermore, we investigated which component between $\mathrm{CP}$ and RA could regulate the TNF- $\alpha$-induced MMP1 expression. HDFs were seeded and pretreated with $250 \mu \mathrm{g} / \mathrm{ml} \mathrm{CP}$ and RA for $3 \mathrm{~h}$, and then exposed to TNF$\alpha$ for $4 \mathrm{~h}$. As shown in Figure 2B, both CP and RA pretreatments significantly inhibited the TNF- $\alpha$-induced MMP1 upregulation in HDFs. Overall, we conclude that EMS pretreatment significantly inhibits TNF- $\alpha-$ induced $M M P 1$ expression in HDFs.

\section{Effect of EMS on IKB degradation and NF-KB transactivation activity}

We investigated whether EMS-mediated inhibition of TNF- $\alpha$-induced MMP1 expression is associated with NF- $\kappa B$ activity in HDFs. First, we confirmed that TNF- $\alpha$ stimulation decreased the protein level of IKB in HDFs (Figure 3A, lane 1 and 3). Next, to investigate the effect of EMS on TNF- $\alpha$-induced IкB degradation, HDFs were seeded and pretreated with 250 and $500 \mu \mathrm{g} / \mathrm{ml}$ EMS before TNF- $\alpha$ stimulation. As shown Figure 3A, pretreatment with EMS rescued the decreased ІкB protein mediated by TNF- $\alpha$ stimulation in HDFs. Third, we also found that the total and nuclear protein level of p65, which is subunit of NF-kB [8], was increased by TNF- $\alpha$ stimulation and the increased p65 protein was largely decreased by EMS pretreated HDFs, indicating that TNF- $\alpha$-induced NF- $\kappa B$ nuclear translocation was inhibited by EMS treatment in HDFs (Figure 3A). Lastly, we further examined whether EMS-mediated inhibition of TNF- $\alpha$-induced p65 nuclear translocation is indeed related with transcriptional activity of NF- $\kappa B$ in HDFs. Using NF- $\mathrm{kB}$ luciferase reporter NIH-3 T3 fibroblasts, we investigated the NF- $\kappa B$ activity after EMS and TNF- $\alpha$ treatment. As shown in Figure 3B, pretreatment with EMS significantly decreased the upregulated luciferase activity mediated by TNF- $\alpha$, indicating that EMS inhibits TNF- $\alpha$-induced NF- $\kappa B$ activation. Notably, TNF- $\alpha$ only stimulation increased the luciferase activity to $3.21 \pm$ 0.31 compared with non-treated control cells; however, EMS pretreatment before TNF- $\alpha$ stimulation increased the luciferase activity only to $2.16 \pm 0.07$ and $1.23 \pm 0.19$ fold compared with non-treated control, respectively (Figure 3B). Therefore, we conclude that EMS inhibits TNF- $\alpha$-induced NF- $\mathrm{kB}$ activation and MMP1 expression in HDFs.

NF- $\mathrm{KB}$ activates transcription of $I L-1 \beta$ and $I L-8$ by binding to their promoters $[11,12]$, leading to inflammation and degradation of the tissue matrix structure by inducing the formation of inflammatory mediators such 


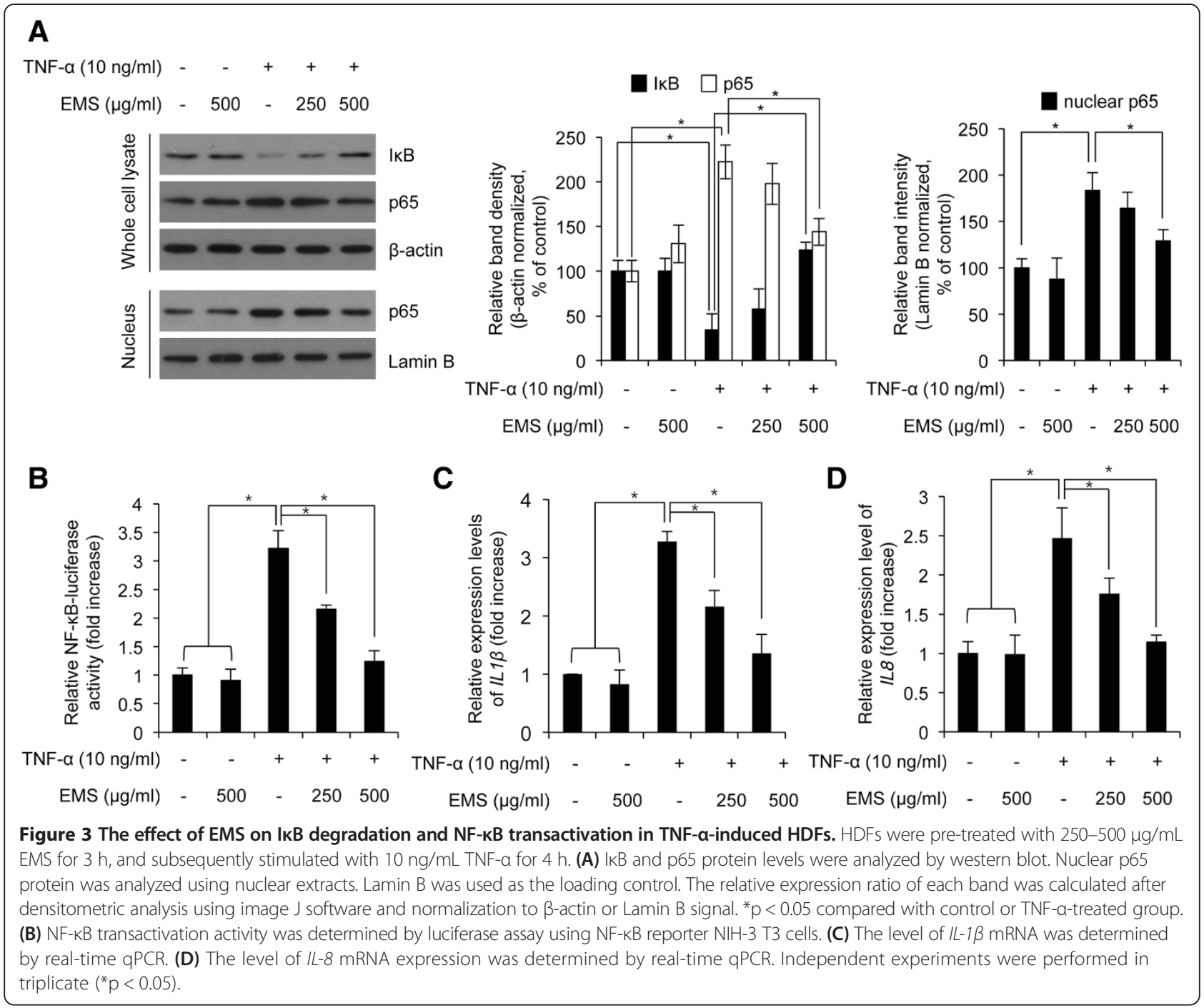

as COX-2, PGE2, and MMP [30]. Thus, we performed qRT-PCR to examine the effect of EMS on IL-1 $\beta$ and IL-8 expression. Our results indicate that the level of IL$1 \beta$ and IL- 8 mRNA increased following TNF- $\alpha$ treatment, but was decreased by EMS in a dose-dependent manner (Figure 3C and D).

\section{Effects of EMS on phosphorylation of MAPK pathway}

To investigate the effect of EMS on the MAPK pathway, ERK, JNK, and p-38 phosphorylation were investigated after treatment with EMS and TNF- $\alpha$ in HDFs. Immunoblotting results showed that pretreatment with EMS did not altered the TNF- $\alpha$-induced phosphorylation of ERK, JNK, and p-38 in HDFs (Figure 4). Therefore, these results showed that the intracellular mechanism of EMSmediated inhibition of TNF- $\alpha$-induced NF- $\mathrm{kB}$ activation and $M M P-1$ expression is independent of the MAPK signaling cascade in HDFs.

\section{Discussion}

Skin is constantly in direct contact with the environment, thereby inducing aging and skin damage [1]. Wrinkle formation, the most representative characteristic of skin aging, is caused by oxidative stress and inflammation of skin cells. Thus, compounds that exhibit an antiinflammatory effect on skin cells have been suggested as promising anti-aging agents [6,7]. In this study, we investigated the inhibitory effect of EMS on inflammationinduced skin aging. Therefore, examination of the effect of EMS on TNF- $\alpha$-induced $M M P-1$ expression in HDFs indicated that pre-treatment with EMS for $3 \mathrm{~h}$ decreased $M M P-1$ mRNA in a concentration-dependent manner (Figure 2A). CP and RA treatment also decreased the expression level of $M M P-1$ mRNA (Figure 2B), suggesting that these active ingredients might synergistically inhibit TNF- $\alpha$-induced $M M P-1$ expression.

The expression of $M M P-1$ in response to inflammation is regulated by the transcription factor NF- $\mathrm{kB}$. In 


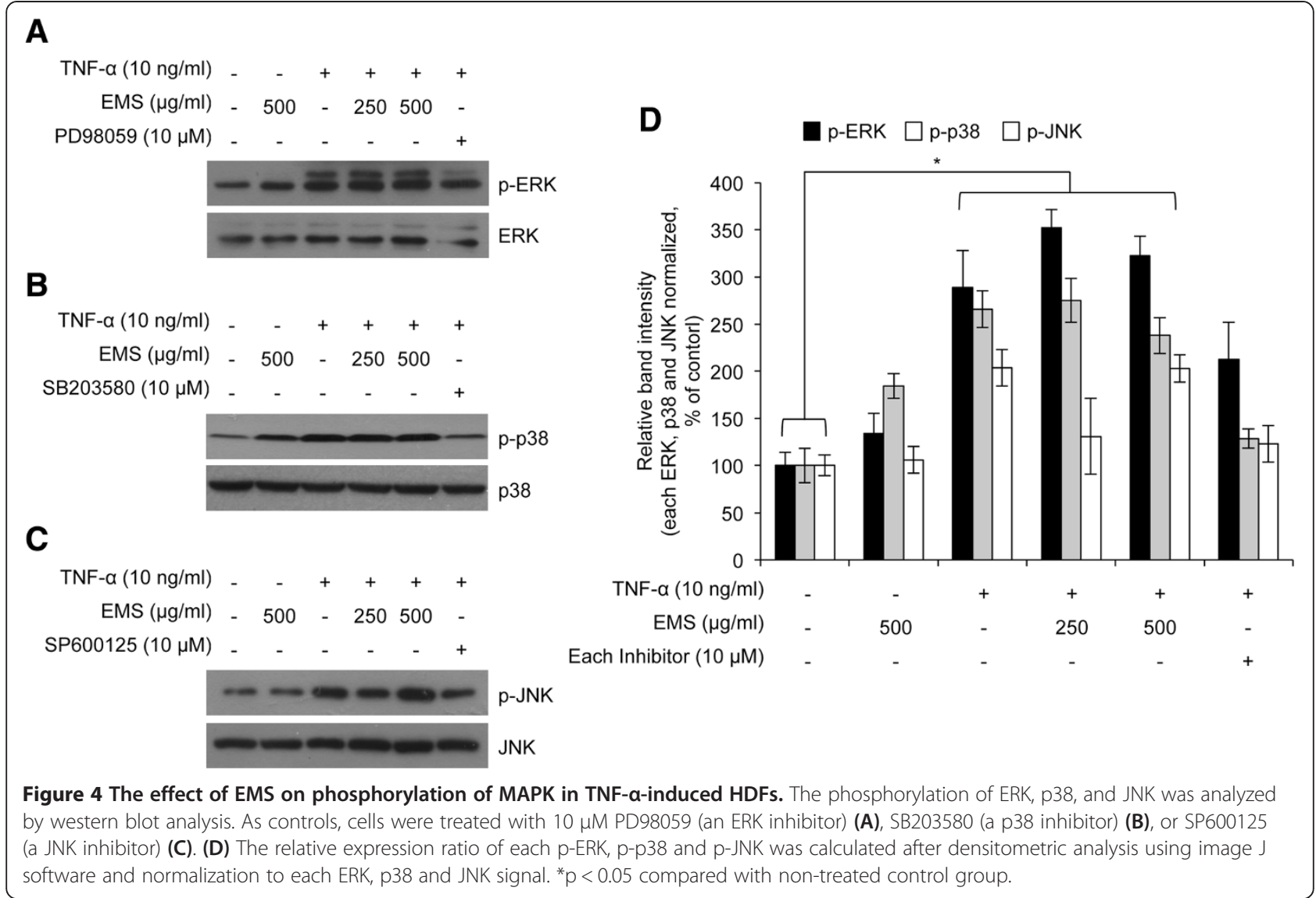

HDFs, NF- $\mathrm{kB}$ activation is involved in regulating inflammation through various intracellular signaling pathways, including the MAPK pathway [30]. MAPKs constitute a group of serine/threonine protein kinases that can be subdivided into three subfamilies: p42/p44 ERK, JNK, and p38 MAPK. MAPKs are activated by various extracellular stimuli and induce the phosphorylation of key signaling molecules associated with cell proliferation, inflammation, and apoptosis [31]. As shown in Figure 4A, $B$ and $C$, we found that EMS inhibited TNF- $\alpha$-induced activation of NF-kB. Also, we found that EMS inhibited TNF- $\alpha$-induced $M M P-1$ expression. The phosphorylation of MAPKs, which is one of NF- $\mathrm{kB}$ activators, was also known to be regulated by TNF- $\alpha$ stimulation [29]. However, we found that the increased levels of phosphorylation of MAPKs by TNF- $\alpha$ stimulation were not changed in EMS-treated cells. Those results indicated that EMSdependent $M M P-1$ expression is not related with the phosphorylation of MAPKs, and EMS-dependent NF- $\mathrm{KB}$ activation would not be dependent on the phosphorylation level of MAPKs. Therefore our results suggest that EMS inhibits the NF- $\mathrm{B}$ pathway independent of the MAPK pathway.

Association of $\mathrm{I} \kappa \mathrm{B}$ with the NF-kB p65/p50 dimer plays an important role in regulating the nuclear translocation and target gene transcription by NF- $\mathrm{kB}$. It is well established that $\mathrm{I} \kappa \mathrm{B}$ degradation induces the nuclear translocation of p65 [8]. Thus, we assessed the level of IкB in TNF- $\alpha$-stimulated HDFs following EMS treatment. Our data show that EMS treatment increased the level of $I_{\kappa} B$ and decreased nuclear p65 (Figure 3A). Nuclear translocation of NF- $\mathrm{kB}$ due to I $\mathrm{B}$ degradation is essential for activating NF- $\mathrm{kB}$ [8]. We further explored this situation by assessing NF- $\mathrm{B}$ transactivation activity. NF- $\kappa \mathrm{B}$ transactivation was found to be increased by TNF- $\alpha$ treatment, but significantly decreased by EMS in a concentration-dependent manner (Figure 4B). In addition, EMS inhibited the expression of $I L-1 \beta$ and $I L$ 8 , which are regulated by NF- $\mathrm{kB}$ (Figure $4 \mathrm{C}, \mathrm{D}$ ). In conclusion, our results demonstrate that EMS exerts its anti-inflammatory effect on skin by inhibiting the TNF$\alpha$-induced expression of $M M P-1$ in HDFs by blocking NF- $\mathrm{kB}$. EMS reduces inflammation by increasing the level of $\mathrm{I}_{\kappa} \mathrm{B}$ present in the cell, which reduces p65 nuclear translocation and thus NF- $\mathrm{kB}$ transactivation. Also, several reports have showed that inhibition of NF- $\mathrm{BB}$ activation suppresses $M M P-1$ expression in several cells including human dermal fibroblasts $[32,33]$. Our data showed that EMS-dependent loss of $M M P-1$ expression was mediated by EMS-mediated inhibitory effect on NF- $\mathrm{kB}$ activation. 
Therefore, our results also suggest that the effect of EMSdependent loss of MMP1 expression might be strengthened by treatment with NF-kB inhibitors.

\section{Conclusions}

In summary, we examined the inhibitory effect of EMS on inflammation-induced NF- $\mathrm{kB}$ activation and MMP1 generation in HDFs. Our data suggest that EMS is a potential anti-aging agent against inflammation-induced skin aging.

\section{Methods}

\section{Herbal extraction and characterization}

Dried CP and RA were obtained from the oriental pharmacy in Kyung Hee Hospital of Oriental Medicine, Kyung Hee University (Seoul, Korea). The each dried sample $(20 \mathrm{~g})$ was added to $200 \mathrm{ml}$ sterilized distilled water (DW) to produce a $10 \%$ solution. For EMS, equal amounts (10 g) of the dried CP and RA were added to $200 \mathrm{ml}$ sterilized DW to be $10 \%$ solution. Those solutions were subsequently extracted for $24 \mathrm{~h}$ at $60^{\circ} \mathrm{C}$ and then filtered. After the extraction and filtration, the extracts were subjected to vacuum evaporating and freeze-drying. Finally, we obtained $3.043 \mathrm{~g}$ of EMS, $2.548 \mathrm{~g}$ of CP, and $2.997 \mathrm{~g}$ of RA, respectively. These powders were dissolved into the tissue cell culture medium and used for experiments.

\section{Cell culture and treatment}

HDFs were obtained from Lonza (Basel, Switzerland) and cultured in Dulbecco's Modified Eagle Medium (DMEM; WELGENE Inc., Daegu, Korea) supplemented with $10 \%$ fetal bovine serum, $100 \mathrm{U} / \mathrm{ml}$ of penicillin, and $100 \mu \mathrm{g} / \mathrm{ml}$ of streptomycin. The cells were maintained at $37^{\circ} \mathrm{C}$ in a $5 \% \mathrm{CO}_{2}$ incubator. TNF- $\alpha$ was purchased from SigmaAldrich (St. Louis, Mo, USA). Cells $\left(1 \times 10^{6}\right.$ or $\left.3 \times 10^{5}\right)$ were seeded in 60 pi or 6 -well cell culture dishes and incubated for overnight. After incubation, the cells were treated with $10 \mathrm{ng} / \mathrm{ml} \mathrm{TNF}-\alpha$ for $4 \mathrm{~h}$ in a serum-free media. All experiments handling human cells were carried out in line with the Tenets of the Declaration of Helsinki.

\section{Quantitative real-time PCR analysis}

CDNAs were synthesized from total RNA using M-MLV reverse transcriptase (Enzynomics, Seoul, Korea) according to the manufacturer's protocol. The forward and reverse primers for human $M M P-1$ were $5^{\prime}$-TCTGAC GTTGATCCCAGAGAGCAG-3' and 5'-CAGGGTGAC ACCAGTGACTGCAC-3', respectively. The forward and reverse primers for human $\beta$-actin were $5^{\prime}$-GGATT CCTATGTGGGCGACGA-3' and $5^{\prime}$-CGCTCGGTGAG GATCTTCATG-3', respectively. The forward and reverse primers for human $I L-1 \beta$ were 5'-ACAGATGAAGTG CTCCTTCCA-3' and 5'-GTCGGAGATTCGTAGCTGG AT-3', respectively. Also the forward and reverse primers for human IL-8 were 5'-ATGACTTCCAAGCTGGCC
GTGGCT-3' and 5' - TCTCAGCCCTCTTCAAAAACT TCTC-3', respectively. PCR was performed using the HOT FIREPol EvaGreen PCR Mix Plus (Solis BioDyne, Estonia) with Line gene $\mathrm{K}$ software (Bioer Technology Co., Ltd., Hangzhou, China). The $\mathrm{C}_{\mathrm{T}}$-value for $M M P-1$, $I L-1 \beta$ and $I L-8$ were normalized to $\beta$-actin. The $2^{-\Delta \Delta C t}$ method was used to calculate relative expression level of $M M P-1, I L-1 \beta$ and $I L-8$. Data were presented as mean \pm S.D. ( $\mathrm{n}=9$; three independent experiments).

\section{Cell viability assay}

Cell viability was assessed using the WST-1 assay according to the manufacturer's instructions (Itsbio, Seoul, Korea). The results are represented graphically as the measured cell viability ratio normalized to the control.

\section{Western blotting}

Cellular proteins was extracted by lysis buffer $(50 \mathrm{mM}$ Tris- $\mathrm{HCl}, \mathrm{pH}$ 8.0, $150 \mathrm{mM} \mathrm{NaCl}, 1 \% \mathrm{NP}-40,0.1 \%$ SDS, and $0.5 \%$ sodium deoxycholate) and EDTA-free protease and phosphatase inhibitor cocktail (Roche, Switzerland). Equal amounts of protein samples were separated by $10 \%$ sodium dodecyl sulfate (SDS) polyacrylamide gel electrophoresis and then transferred onto nitrocellulose membrane (Whatman Protan BA83, GE Healthcare Life Science, Freiburg, Germany). After blocking with 5\% skim milk for $1 \mathrm{~h}$ at room temperature, the membranes were incubated first with primary antibody at $4^{\circ} \mathrm{C}$ overnight and subsequently with peroxidase-conjugated secondary antibody at room temperature for $1 \mathrm{~h}$. The protein bands were detected using enhanced chemiluminescence reagents. Primary antibody specific for MMP1 NF-kB-p65, $\mathrm{I} \kappa \mathrm{B}$ and Lamin B were purchased from Santa Cruz Biotechnology (Santa Cruz, CA, USA). Anti- $\beta$-actin antibody was purchased from Sigma-Aldrich (St. Louis, MO, USA). Anti-p38, p38, pERK, ERK, pJNK and JNK were purchased from Cell Signaling Technology (Danvers, MA, USA).

\section{Preparation of nuclear protein extracts}

Cells were gently resuspended in $500 \mu \mathrm{l}$ of buffer $\mathrm{A}$ (10 mM HEPES, pH 7.5, $1.5 \mathrm{mM} \mathrm{MgCl}_{2}, 10 \mathrm{mM} \mathrm{KCl}$, $0.5 \mathrm{mM}$ DTT, and $0.05 \% \mathrm{NP}-40$ ) and then incubated for $20 \mathrm{~min}$ on ice. The cells were centrifuged for $5 \mathrm{~min}$ at $3,000 \times \mathrm{g}$ at $4^{\circ} \mathrm{C}$. Then, $25 \mu \mathrm{l}$ of buffer B (1\% Triton X100, $300 \mathrm{mM} \mathrm{NaCl}, 5 \mathrm{mM}$ HEPES, pH 7.5, $1.5 \mathrm{mM}$ $\mathrm{MgCl}_{2}, 0.2 \mathrm{mM}$ EDTA, $0.5 \mathrm{mM}$ DTT, and 26\% glycerol) was added, and the samples were mixed prior to centrifugation for $20 \mathrm{~min}$ at $12,000 \times \mathrm{g}$ at $4^{\circ} \mathrm{C}$. The supernatant (nuclear protein extract) was collected and stored at $-80^{\circ} \mathrm{C}$ until use. 


\section{NF-KB transactivation activity assay}

NF- $\kappa$ B-luciferase reporter stable NIH-3 T3 cell line, which was stably transfected with the NF- $\mathrm{kB}$-luciferase reporter vector (pNF-kB-luc; Affymatrix-Panomics, Santa Clara, CA, USA), was purchased from Affymatrix-Panomics. pNF- $k \mathrm{~B}-$ luc was designed to measure the transcriptional activity of NF-kB. Six copies of NF- $\mathrm{kB}$ binding sequences (5' -GGGAATTTCCGGGAATTTCCGGGAATTTCCGGGAATTTCCGGGAATTTCCGGGAATTTCC-3') were subcloned into the upstream region of luciferase cDNA. The NIH-3 T3/NF-kB-luc cell line was obtained by cotransfection of pNF-kB-luc (Affymatrix-Panomics) and pHyg into NIH-3 T3 cells, followed by hygromycin selection. To test NF- $\mathrm{kB}$ activity, approximately $1 \times 10^{5} \mathrm{NF}-\mathrm{\kappa B}$ reporter NIH-3 T3 stable cells were seeded onto $60-\mathrm{mm}$ culture dishes and cultured for $24 \mathrm{~h}$. Cells were then lysed by adding Passive Lysis Buffer (Promega, Madison, WI, USA) and incubating for $30 \mathrm{~min}$ on ice. After centrifugation for $30 \mathrm{~min}$ at $12,000 \times \mathrm{g}$ at $4^{\circ} \mathrm{C}$, the supernatant was collected. The cell lysate was treated with luciferin (Promega) and its luminescence was measured using a Veritas Luminometer (Turner Designs, Sunnyvale, CA, USA). Results shown are the averages of three independent experiments.

\section{Statistical analysis}

A result of three observations per group was subjected to a statistical analysis. Data are presented as mean \pm the standard deviation (S.D.). Statistical analysis was performed using two-tailed Student's $t$-test analysis. $\mathrm{P}<0.05$ was considered significant.

\section{Competing interests}

The authors declare that they have no competing interests.

\section{Authors' contributions}

SB, YJ perform the experiments and Figures. YMC and SL: Experimental design and advising. SB and SL: Experimental design and write the manuscript. All authors read and approved the final manuscript.

\section{Acknowledgements}

This paper was supported by the KU Research Professor Program of Konkuk University and a grant from the Korean Health Technology R\&D Project (Grant No. HN13C0080), Ministry of Health \& Welfare, Republic of Korea.

\begin{abstract}
Author details
${ }^{1}$ Korea Institute for Skin and Clinical Sciences and Molecular-Targeted Drug Research Center, Konkuk University, Seoul, Republic of Korea. ${ }^{2}$ Department of Bioengineering, Graduate School of Konkuk University, Seoul, Republic of Korea. ${ }^{3}$ Department of Beauty Education, Graduate School of Education, Konkuk University, 120 Neungdong-ro, Gwangjin-gu, Seoul 143-701, Republic of Korea.
\end{abstract}

Received: 22 September 2014 Accepted: 8 January 2015

Published: 26 January 2015

\section{References}

1. Farage MA, Miller KW, Elsner $\mathrm{P}$, Maibach $\mathrm{HI}$. Intrinsic and extrinsic factors in skin ageing. Int J Cosmetic. 2008;30:87-95.

2. Li Y, Bi Z, Yan B, Wan Y. UVB radiation induces expression of HIF-1alpha and VEGF through the EGFR/PI3K/DEC1 pathway. Int J Mol Med. 2006;18:713-9.
3. Fisher GJ, Kang S, Varani J, Bata-Csorgo Z, Wan Y. Mechanisms of photoaging and chronological skin aging. Arch Dermatol. 2002;138:1462-70.

4. Egbert M, Ruetze M, Sattler M, Wenck H, Gallinat S. The matricellular protein periostin contributes to proper collagen function and is downregulated during skin aging. J Dermatol Sci. 2014;73:40-8.

5. Talwar HS, Griffiths CE, Fisher GJ, Hamilton TA, Voorhees JJ. Reduced type I and type III procollagens in photodamaged adult human skin. J Invest Dermatol. 1995; 105:285-90.

6. Lee YR, Noh EM, Jeong EY, Yun SK, Jeong YJ, Kim JH, et al. Cordycepin inhibits UVB-induced matrixmetalloproteinase expression by suppressing the NF-kappaB pathway in human dermal fibroblasts. Exp Mol Med. 2009;41:548-54.

7. Lee YR, Noh EM, Han JH, Kim JM, Hwang JK, Hwang BM, et al. Brazilin inhibits UVB-induced MMP-1/3expressions and secretions by suppressing the NF-kappaB pathway in human dermal fibroblasts. Eur J Pharmacol. 2012;674:80-6.

8. Bharti AC, Aggarwal BB. Nuclear factor-kappa B and cancer: its role in prevention and therapy. Biochem Pharmacol. 2002;64:883-8.

9. Beg AA, Ruben SM, Scheinman RI, Haskill S, Rosen CA, Baldwin Jr AS. I kappa $B$ interacts with the nuclear localization sequences of the subunits of NF-kappa B: a mechanism for cytoplasmic retention. Genes Dev. 1992;6:1899-913.

10. Pennington KN, Taylor JA, Bren GD, Paya CV. IkappaB kinase-dependent chronic activation of NF-kappaB is necessary for p21 (WAF1/Cip1) inhibition of differentiation-induced apoptosis of monocytes. Mol Cell Biol. 2001;21:1930-41.

11. Cogswell JP, Godlevski MM, Wisely GB, Clay WC, Leesnitzer LM, Ways JP, et al. NF-kappa B regulates IL-1 beta transcription through a consensus NF-kappa B binding site and a nonconsensus CRE-like site. J Immunol. 1994;153:712-23.

12. Kunsch C, Rosen CA. NF-kappa B subunit-specific regulation of the interleukin-8 promoter. Mol Cell Biol. 1993;13:6137-46.

13. Bond $M$, Baker AH, Newby AC. Nuclear factor kappaB activity is essential for matrix metalloproteinase-1 and -3 upregulation in rabbit dermal fibroblasts. Biochem Biophys Res Commun. 1999;264:561-7.

14. Visse $R$, Nagase $H$. Matrix metalloproteinases and tissue inhibitors of metalloproteinases: structure, function, and biochemistry. Circ Res. 2003;92:827-39.

15. Tanaka K, Hasegawa J, Asamitsu K, Okamoto T. Prevention of the ultraviolet B-mediated skin photoaging by a nuclear factor kappaB inhibitor, parthenolide. J Pharmacol Exp Ther. 2005;315:624-30.

16. Dasu MR, Barrow RE, Spies M, Herndon DN. Matrix metalloproteinase expression in cytokine stimulated human dermal fibroblast. Burns. 2003:29:527-31.

17. Nishida S, Kikuichi S, Yoshioka S, Tsubaki M, Fujii Y, Matsuda H, et al. Induction of apoptosis in $\mathrm{HL}-60$ cells treated with medicinal herbs. Am J Chin Med. 2003;31:551-62.

18. Yi P, Lu FE, Xu LJ, Chen G, Dong H, Wang KF. Berberine reverses free-fattyacid-induced insulin resistance in 3 T3-L1 adipocytes through targeting IKKbeta. World J Gastroenterol. 2008;14:876-83.

19. Hu JP, Nishishita K, Sakai E, Yoshida H, Kato Y, Tsukuba T, et al. Berberine inhibits RANKL-induced osteoclast formation and survival through suppressing the NF-kappaB and Akt pathways. Eur J Pharmacol. 2008;580:70-9.

20. Resch M, Steigel A, Chen ZL, Bauer R. 5-Lipoxygenase and cyclooxygenase-1 inhibitory active compounds from Atractylodes lancea. J Nat Prod. 1998;61:347-50.

21. Auerbach BJ, Kiely JS, Cornicelli JA. A spectrophotometric microtiter-based assay for the detection of hydroperoxy derivatives of linoleic acid. Anal Biochem. 1992;201:375-80.

22. Fiddler Gl, Lumley P. Preliminary clinical studies with thromboxane synthase inhibitors and thromboxane receptor blockers. Circulation. 1990;81:169-178.

23. Du CY, Choi RC, Zheng KY, Dong TT, Lau DT, Tsim KW. Yu Ping Feng San, an ancient Chinese herbal decoction containing Astragali Radix, Atractylodis Macrocephalae Rhizoma and Saposhnikoviae Radix, regulates the release of cytokines in murine macrophages. PLoS One. 2013;8:e78622.

24. Zhong XH, Zhou ZX, Li TS, Wang EQ, Shi WY, Chu SM. Anti-abortive effect of Radix scutellariae and Rhizoma atractylodis in mice. Am J Chin Med. 2002;30:109-17.

25. Boes S, Kim H. Evaluation of In Vitro Anti-Inflammatory Activities and Protective Effect of Fermented Preparations of Rhizoma Atractylodis Macrocephalae on Intestinal Barrier Function against Lipopolysaccharide Insult. Evid Based Complement Alternant Med. 2013;2013:363076.

26. Liao J, Li PP, Wu CJ. Screening new photosensitizers from Chinese medicinal herbs and searching for herbal photodynamic killing effects on human stomach cancer cells. Zhongguo Zhong Xi Yi Jie He Za Zhi. 1997;17:726-9.

27. Xu Q, Yuan K, Lu J, Wang R, Wu F. A new strategy for regulating the immunological liver injury-effectiveness of DTH-inhibiting agents on DTH- induced liver injury to picryl chloride. Pharmacol Res. 1997;36:401-9. 
28. Kim HH, Shin $\mathrm{CM}$, Park $\mathrm{CH}$, Kim KH, Cho KH, Eun HC, et al. Eicosapentaenoic acid inhibits UV-induced MMP-1 expression in human dermal fibroblasts. J Lipid Res. 2005;46:1712-20.

29. Vanden Berghe W, Plaisance S, Boone E, De Bosscher K, Schmitz ML, Fiers W, et al. p38 and extracellular signal-regulated kinase mitogen-activated protein kinase pathways are required for nuclear factor-kappaB p65 transacitivation mediated by tumor necrosis factor. J Biol Chem. 1998;273:3285-90.

30. Lu Y, Wahl LM. Oxidative stress augments the production of matrix metalloproteinase-1, cyclooxygenase-2, and prostaglandin E2 through enhancement of NF-kappa B activity in lipopolysaccharide-activated human primary monocytes. J Immunol. 2005;175:5423-9.

31. Kim EK, Choi EJ. Pathological roles of MAPK signaling pathways in human diseases. Biochem Biophys Acta. 1802;2010:396-405.

32. Hong MJ, Ko EB, Park SK, Chang MS. Inhibitory effect of Astragalus membranaceus root on matrix metalloproteinase-1 collagenase expression and procollagen destruction in ultraviolet B-irradiated human dermal fibroblasts by suppressing nuclear factor kappa-B activity. J Pharm Pharmacol. 2013;65:142-8.

33. Bond M, Chase AJ, Baker AH, Newby AC. Inhibition of transcription factor NF-kappaB reduces matrix metalloproteinase- $1,-3$ and -9 production by vascular smooth muscle cells. Cardiovasc Res. 2001;50:556-65.

doi:10.1186/0717-6287-48-8

Cite this article as: Bae et al:: Effects of Er-Miao-San extracts on

TNF-alpha-induced MMP-1 expression in human dermal fibroblasts.

Biological Research 2015 48:8.

\section{Submit your next manuscript to BioMed Central and take full advantage of:}

- Convenient online submission

- Thorough peer review

- No space constraints or color figure charges

- Immediate publication on acceptance

- Inclusion in PubMed, CAS, Scopus and Google Scholar

- Research which is freely available for redistribution 